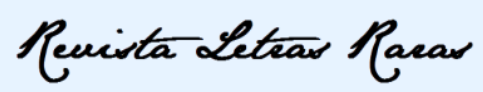

ISSN: 2317-2347 - v. 7, n. 1 (2018)

\title{
Desacomodações contemporâneas: entrevista com Clóvis Da Rolt
}

\author{
André Tessaro Pelinser* \\ Letícia Malloy**
}

No início de seu ensaio intitulado O que é o contemporâneo?, Giorgio Agamben oferece uma definição segundo a qual "contemporâneo é aquele que mantém fixo o olhar no seu tempo, para nele perceber não as luzes, mas o escuro.” (AGAMBEN, 2009, p. 62) Na sua perspectiva, trata-se justamente de conseguir ver o que está obscurecido em cada época e ser capaz de escrever mergulhando a pena nas trevas do presente, compreendendo o escuro do tempo como algo que nos concerne e que não cessa de nos interpelar. (AGAMBEN, 2009, p. 63-64) Ser contemporâneo, portanto, implica não apenas compartilhar um momento presente, mas um modo de ver esse momento; pressupõe a habilidade de separar e neutralizar as luzes de cada época para então examinar as suas trevas. Para Agamben, em suma, um "homem inteligente pode odiar o seu tempo, mas sabe, em todo caso, que lhe pertence irrevogavelmente, sabe que não pode fugir ao seu tempo." (AGAMBEN, 2009, p. 59)

A contemporaneidade, por esse prisma, não se afigura confortável e cômoda. Pelo contrário, torna-se fruto de um incômodo permanente, que compele o indivíduo a examinar as fissuras de seu tempo, atribuindo-lhes sentidos divergentes daqueles apresentados pelo status quo e significados distintos daqueles esperados pelos demais sujeitos. Visualizar e mergulhar nas rachaduras do tecido social de cada época, examinando o que se esconde na escuridão, tem sido uma das funções da arte ao longo dos séculos. Ao lado dos artistas, têm se destacado nessa mesma tarefa intelectuais das chamadas Ciências Humanas, que igualmente perscrutam as narrativas e os fenômenos sociais em busca, senão de explicações, de fornecer problematizações à realidade humana. Não estranha que Clóvis Da Rolt, professor, poeta e artista plástico nascido em Bento Gonçalves-RS, em 1976, seja tanto licenciado em Artes Plásticas pela Universidade de Caxias do Sul (UCS), como mestre e doutor em Ciências Sociais pela

\footnotetext{
* Professor adjunto de Literatura Brasileira na Universidade Federal do Rio Grande do Norte, campus de Currais Novos. Endereço eletrônico: andre.pelinser@gmail.com

** Professora adjunta I de Literaturas de Língua Inglesa na Universidade do Estado do Rio Grande do Norte. Endereço eletrônico: leticiamalloy@gmail.com
} 


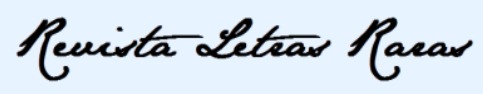

ISSN: $2317-2347$ - v. 7, n. 1 (2018)

Universidade do Vale do Rio dos Sinos (Unisinos). Atualmente professor da Universidade Federal do Pampa, Da Rolt foi também bolsista da Fundação Carolina na Universidade de Granada, na Espanha, durante o doutorado, e manteve por seis anos uma coluna semanal no Jornal Gazeta, de Bento Gonçalves-RS.

Embora Clóvis Da Rolt pertença à recente geração de poetas brasileiros que começou a publicar a partir dos anos 2000, seu contato com o universo artístico se deu antes por intermédio das artes plásticas. Entre 1997 e 2003, participou de exposições coletivas promovidas pela Fundação Casa das Artes, em Bento Gonçalves-RS, das quais se destaca a apresentação, no ano 2000, do primeiro trabalho de videoarte da cidade, intitulado Vento eletrônico. Em seguida, após um hiato de cinco anos, Da Rolt realizou sua primeira exposição individual. Chamada Desvios para o nunca, a mostra foi aberta em 2008, na galeria da Fundação Casa das Artes, e em 2009, na Unisinos, em São Leopoldo-RS. Nesses dois momentos, seu trabalho caracterizava-se por uma reflexão sobre a linguagem e a criação do sentido das palavras em sua relação concreta com o mundo, segundo o próprio autor.

No que se refere ao universo literário, a estreia do autor ocorreu em 2004, com o volume intitulado Canção de Vidro, editado com financiamento da Fundação Casa das Artes, de Bento Gonçalves. Dois anos depois, em conjunto com os poetas João Claudio Arendt, Douglas Ceccagno e Marli Tasca Marangoni, Da Rolt publicou Calendário Antologia poética do Grupo Neblina, volume coletivo contendo os poemas dos quatro integrantes do grupo. Em 2014, depois de concluído o doutorado e já atuando como professor na Unipampa, Clóvis Da Rolt publicou em edição própria o volume intitulado Universo. Sua obra mais recente, A orientação das serpentes, publicada pela Editora Modelo de Nuvem em 2016, foi finalista do Prêmio Açorianos de Literatura de 2016. Em anos anteriores, participou do Prêmio Lila Ripoll de Poesia, promovido pela Assembleia Legislativa do Estado do RS, obtendo menção honrosa na edição de 2005 e a segunda colocação e menção honrosa em 2009.

Ao longo desse percurso, como pode ser verificado a partir dos excertos de poemas presentes em algumas das questões a seguir, Da Rolt aperfeiçoou uma singular capacidade de perquirir as trevas de nosso século, trazê-las à tona e apresentá-las por meio de um fazer poético que não se furta a voltar-se sobre si mesmo. Sua poesia não oferece conforto, tampouco mostra condescendência em relação à experiência de estar 


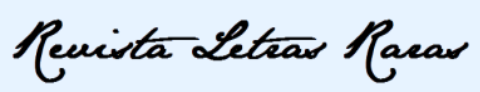

ISSN: 2317-2347 - v. 7, n. 1 (2018)

no mundo. Na entrevista a seguir, realizada no âmbito do projeto de extensão Notícia da atual literatura brasileira: entrevistas, Clóvis Da Rolt reflete a respeito de seu processo de composição artística, lança um olhar crítico sobre o momento atual do ensino universitário brasileiro e sobre os espaços de fronteira e compartilha com o leitor sua análise de questões candentes deste início de século, como o lugar do intelectual e da arte em um mundo cada vez mais midiatizado e imediatista.

Cada escritor possui um modus operandi, por assim dizer. Em seu trabalho, é possível perceber uma característica marcante, a que poderíamos nos referir como uma "poética da descrença", que bem poderia ser ilustrada pelos seguintes versos de um poema que lemos na seção "Comboio das imagens", de $A$ orientação das serpentes (2016): “Em algum lugar um corpo sumirá na penumbra, / mais uma lágrima se juntará ao álbum de família: / será judeu, muçulmano ou cristão? / Em vão espero a chuva construir desvios / para outro século." Você poderia nos falar um pouco sobre as opções formais e temáticas que norteiam seu projeto literário?

O fazer poético, no meu entendimento, se dá numa constante revisão dos percursos trilhados por um autor. Digo isso no sentido de sugerir que não penso em temáticas ou opções formais que sejam especificamente minhas, que sirvam para tudo o que fiz ou farei daqui para adiante. Há sempre o risco de cairmos em maneirismos quando somos tentados pela "fórmula" que funciona. Sou movido por desacomodações, observo as coisas à minha volta, tento significá-las pela via poética. Nesse sentido, todas as opções são válidas, todos os temas estão disponíveis. A poesia depende sempre de um momento, de uma ênfase, de uma urgência. E isso pode não encaixar-se no que foi construído (formal ou tematicamente) dentro de uma trajetória. O que me parece é que, por uma questão condicionante que lhe é própria, a poesia acaba revelando a singularidade de escolhas de quem a produz. De um modo muito genérico, posso dizer que tenho um interesse pela construção da linguagem poética, seu caráter de revelação, as relações que conduzem o seu dizer e o seu fazer, a metapoesia. Enfim, tenho interesse por aquilo que torna a poesia possível. 


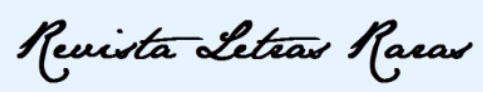

ISSN: 2317-2347 - v. 7, n. 1 (2018)

Em um dos poemas dispostos na seção "Inventário das distâncias", de A orientação das serpentes (2016), o eu-lírico afirma: "Preciso reinventar a palavra que apodreceu / sem ter sido digerida, / refazer o caminho que me envelheceu / antes que eu pudesse ser sábio." Em que medida esses versos dizem de seu processo criativo?

A poesia é notável por seus contrastes: por um lado, pode não alcançar o que promete; por outro, pode atingir o que nunca pretendeu. É trabalhoso lidar com esta maleabilidade da poesia, com sua natureza escorregadia e imprevisível. Assim, cada poema é um recomeço, algo que se revela num estado originário, sobre o qual nada se sabe. Eu nunca sei por onde começar. Nunca sei quando surgirá outro poema. Mas, paradoxalmente, sempre há o próximo poema... É como se cada poema fosse do Gênesis ao Apocalipse: cabe tudo dentro dele. Este é o dilema com o qual todo poeta tem que lidar, pois o poeta é alguém que faz escolhas com a linguagem. Em geral, todas as palavras utilizadas num poema estão indexadas nos dicionários da língua em que foi escrito. Mas a poesia não é apenas um amontoado de palavras. Consiste, antes, numa ignição simbólica tornada possível pelo encontro criativo das palavras, especialmente quando o inesperado salta deste encontro. Meu processo gira em torno da palavra, do enunciado, das fraturas do sentido, da temporalidade do que se enquadra no discurso poético.

Em sua trajetória literária, você publicou o livro de poemas Canção de vidro (2004), em seguida participou do Grupo Neblina, do qual resultou o volume coletivo intitulado Calendário - antologia poética do Grupo Neblina (2006), e recentemente voltou à poesia com $A$ orientação das serpentes (2016), que foi finalista do Prêmio Açorianos de Literatura em 2016. Houve um momento inaugural ou o caminho se fez gradualmente? Em que momento da vida você se percebeu um escritor?

Creio que tudo foi acontecendo sem premeditação, mediante um acúmulo de experiências, de interlocuções com pessoas que partilham interesses literários e de inserções na linguagem poética (lendo poemas, analisando estruturas e formas, 


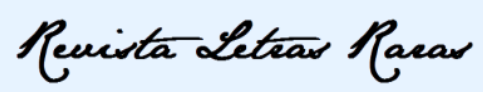

ISSN: 2317-2347 - v. 7, n. 1 (2018)

estudando questões filosóficas, comparando estilos e dicções). Nunca foi meu interesse ser um "profissional" da escrita. Almejo tão somente dar uma resposta, para mim mesmo, para o espanto e a estranheza que é existir. Escrever é reaprender a olhar para o mundo deixando de lado tudo o que os outros fizeram você acreditar que o mundo era. É como trocar de pele, reformular aparentes certezas, redesignar o que se julgava sabido. Assim, penso que há um momento em que você percebe que se esvaziou de conteúdos alheios. No meu caso, foi neste momento que a poesia parece ter se instalado com mais maturidade.

Você é também artista plástico, tendo realizado exposições individuais, muitas vezes com obras marcadas por uma reflexão sobre a própria linguagem. As artes plásticas desempenham alguma influência em sua aproximação ao objeto literário?

Minha atividade nas artes plásticas foi exígua, fragmentária e pouco consistente. Por isso mesmo, abandonei esta atividade. Em arte não há nada mais desolador do que não forjar uma linguagem; nada mais perturbador do que querer dizer alguma coisa sem ter algo a dizer (ou não saber como dizer dentro de uma forma artística). Arte é forma. Só há arte onde se elabora uma forma nova, inaugural, que rompe com o que já conhecemos e sabemos. Por isso mesmo estamos presenciando tantos engodos artísticos no mundo atual, cujo âmbito estético, de um ponto de vista criativo, opera na lógica do insight. Os artistas não se empenham mais na construção de uma linguagem; visam apenas o estalo de uma ideia momentânea e o imediatismo de uma encenação de valor. O banal foi elevado à condição de memória e de registro cultural. Sou uma pessoa muito marcada pela visualidade. Talvez, de algum modo, isso esteja presente em meus poemas. Além disso, foi por meio das artes plásticas que o fenômeno artístico instalouse como uma necessidade vital para mim.

Como você avalia a recepção de sua obra? Fale-nos um pouco sobre a recepção de sua obra poética e, se possível, sobre a recepção de seus trabalhos em artes plásticas. Ser finalista do Prêmio Açorianos de 2016 influenciou o reconhecimento da sua literatura? 


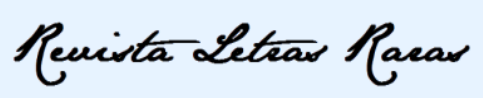

ISSN: 2317-2347 - v. 7, n. 1 (2018)

Para ser sincero, não costumo me ater a essas questões. Eu sequer posso dizer que tenho uma "obra", pois esta palavra sugere um peso muito grande, que beira uma consagração à qual não faço jus. Quem tem uma obra é João Cabral de Melo Neto, Guimarães Rosa, Lygia Fagundes Telles... Publico pouco, num ritmo lento, sem cobranças. Gilles Deleuze dizia que não possuía "conhecimento de reserva", que sempre que precisava escrever sobre algo, punha-se a estudar. Essa ideia me atrai. Estou sempre concentrado no que tenho que estudar hoje para produzir alguma coisa. Mas há autores que, ao contrário, assinam contratos com editoras já prevendo o intervalo "necessário" entre um trabalho e outro, tudo pautado por estatísticas de consumo do mercado editorial. Isso é horroroso. O que publiquei até hoje circulou num âmbito mais regional, no interior do Rio Grande do Sul. Se há uma recepção, penso que ela se manteve num âmbito mais localizado. Não ligo muito para divulgação, recepção e visibilidade. Eu apenas escrevo; o destino da escrita não depende de mim. O livro A orientação das serpentes acabou tendo um pouco mais de visibilidade. Isso certamente se deve ao fato de ter sido publicado por uma editora de Porto Alegre e da indicação ao Açorianos. Recentemente, uma resenha sobre o livro foi publicada na Revista Filosofia (Ed. Escala, $n^{\circ}$ 130). Também em função deste livro, dois ensaios me foram encomendados para

publicação em dois volumes sob organização da Profa. Ana Haddad Baptista, da Universidade Nove de Julho. A Profa. Ana ainda adotou o livro para trabalhar com seus alunos numa disciplina de literatura contemporânea.

Durante alguns anos, você foi colunista de um jornal de Bento Gonçalves, na Serra Gaúcha, redigindo crônicas e textos de opinião densos, capazes de desacomodar o leitor. Em que medida a obrigatoriedade de manter um exercício de reflexão constante em um espaço como o do jornal pode contribuir para o fazer artístico?

Fui colunista durante seis anos, assinando uma coluna semanal. Esta inserção no jornal - que foi totalmente voluntária - ensinou-me que este veículo tem um ritmo, uma forma e uma natureza muito peculiares. O colunista é alguém que esperamos ansiosamente ler; queremos saber o que ele pensa; temos a necessidade de conferir qual é a sua avaliação sobre um "tema quente" sobre o qual todos estão falando. Sabemos que um colunista é bom quando compramos (ou assinamos) um jornal somente por sua 


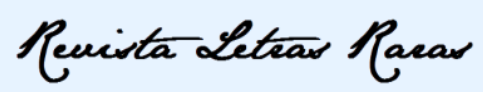

ISSN: 2317-2347 - v. 7, n. 1 (2018)

causa, ou quando ficamos ansiosos pela próxima coluna, como se um oráculo nos falasse e nos ajudasse a abrir os olhos. Entretanto, o colunista é alguém que fica muito exposto e que, muitas vezes, corre o risco de tornar-se repetitivo diante dos temas e ênfases que adota em sua escrita. $O$ colunismo não dá muito espaço para experimentações, já que sua natureza reside numa comunicação mais direta, opinativa e persuasiva. Talvez os leitores já esperem do colunista este tipo de dinâmica. A experiência da escrita, quando feita com prazer, responsabilidade e compromisso ético será sempre um fermentário de ideias que podem ser trabalhadas em diferentes gêneros e canais de circulação.

Você é originário da Serra Gaúcha, localizada no nordeste do Rio Grande do Sul, e há alguns anos se mudou para o sul do estado, para a região dos pampas. Em sua produção poética anterior e posterior à experiência de mudança, podemos verificar uma constante: sua poesia se caracteriza por um tom ácido e, às vezes, desiludido sobre a humanidade. Você percebe alguma influência dos dois espaços geográficos na formação dessa sua visão?

Pessoas são pessoas em qualquer lugar. Onde quer que estejamos, sempre nos envolverão as mesmas questões. Porém, os lugares, os contextos e as variações territoriais exprimem singularidades que se conectam a um drama humano maior. De fato, a própria humanidade - este termo é muito vago e impreciso - não me dá muitos motivos para ser otimista. Creio que essa tônica de algum modo se dilui no que escrevo. Não creio, contudo, que a poesia seja eficiente para delatar ou corrigir o que somos. Ela mostra, propõe, interroga, funciona como um alerta; mas se descambar para o moralismo e a prescrição, corre o risco de se tornar panfletária. E não há nada mais detestável do que uma poesia que almeje ser um recurso à correção ou à indução de comportamentos. Acredito que minha mudança para o pampa gaúcho acabou me inserindo, inevitavelmente, em um novo cenário humano, social e cultural. Contra isso não há formas de blindagem. E nem deveria haver. Portanto, aproveito a desacomodação causada pela mudança para redescobrir a extensão do meu fazer poético, pois a todo momento sou confrontado por ela. 


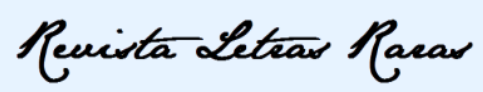

ISSN: 2317-2347 - v. 7, n. 1 (2018)

Desde 2011, você atua como professor na Universidade Federal do Pampa, campus Jaguarão. Em que medida a experiência de residir em uma cidade fronteiriça do país, a maior proximidade com a língua espanhola e os diálogos com traços da cultura uruguaia participam de seu fazer artístico?

As fronteiras são espaços singulares, de onde brotam fenômenos culturais sui generis. No caso dos intercursos entre Jaguarão (Brasil) e Río Branco (Uruguai), há um dinamismo sociocultural que se verifica, dentre outras situações, nos fluxos humanos e comerciais em torno da Ponte Mauá; na linguagem escrita e falada que, muitas vezes, mescla estruturas linguísticas do português e do espanhol; nas oscilações referentes ao câmbio do dólar (em função da zona de freeshops instalada em Río Branco); no trânsito de conteúdos estéticos (música, televisão, carnaval, imaginários contextuais) e nas disputas simbólicas que parecem gerar uma "terceira margem" - numa alusão ao texto de Guimarães Rosa e ao próprio rio Jaguarão. Sem dúvida, há uma dimensão positiva nestes intercursos, que, inclusive, pode ser elaborada artisticamente. Mas a fronteira aqui enquadrada, há que se registrar, é também marcada por abandono, carência de recursos e descaso das instâncias governamentais. Do ponto de vista da criação, é impossível ficar indiferente a um espaço onde as formas de mestiçagem cultural fazem parte do cotidiano. Entretanto, não me vejo, ao menos neste momento, elaborando tais formas a fim de alçá-las a uma linguagem poética. Também não penso em produzir uma poesia que nasça da "obrigação" de escrever sobre este contexto. Digo isso porque pode haver uma expectativa de que um autor, pelo fato de viver numa fronteira, tenha que, necessariamente, tomá-la como objeto de criação. Sou movido por aquilo que a poesia demanda de mim. É ela quem está no comando. Se, de algum modo, a fronteira aparecer em minha escrita futura, será através de um percurso de amadurecimento e não apenas como uma encenação ou uma apropriação forçada.

Você poderia nos falar um pouco a respeito de seu processo de reflexão sobre a docência - principalmente a docência voltada à arte - em uma Universidade situada na fronteira com o Uruguai, distante de centros culturais e acadêmicos hegemônicos brasileiros? 


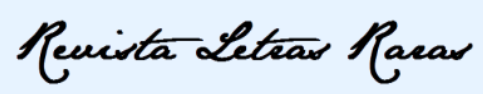

ISSN: 2317-2347 - v. 7, n. 1 (2018)

A universidade pública brasileira está em franca decadência. Parece-me que ela perdeu o seu sentido de necessidade e o seu compromisso educativo. Trata-se de uma questão não apenas da instituição, mas de uma crise no modelo formativo e nas bases conceituais e filosóficas da educação superior. Não percebo em nossas universidades um sentido profundo de "formação" para a vida e para a autonomia do indivíduo. Muitas universidades existem hoje para cumprirem a função de centros de assistência social, onde a produção do conhecimento, a pesquisa, o pensamento e a reflexão crítica sobre as ciências, as artes e a cultura converteram-se em extravagâncias. Uma evidência disso é a irrelevância do Brasil no cenário acadêmico internacional, com raras exceções (raras mesmo!) em algumas áreas. Sem dúvida, isso fica mais claro diante do colonialismo acadêmico que impera no Brasil, cuja lógica acentua ainda mais as diferenças entre os centros hegemônicos e as periferias. O sistema de seleção do alunado (ENEM, SISU) é, por si só, um estímulo à manutenção deste desequilíbrio. Em suma, melhores notas nestes processos de seleção garantem vagas nas universidades centrais. Candidatos à docência, muitas vezes, se negam a prestar concursos em locais afastados de um centro mais estabelecido. Há uma mística de que as universidades periféricas - no caso da Unipampa a fronteira é um elemento paradigmático - são indutoras de progresso e desenvolvimento, mas o que percebo depõe contra essa visão. Com a vinda da universidade, a cidade de Jaguarão foi tomada por uma especulação imobiliária sem precedentes; o transporte público é precário; não há postos de trabalho para os alunos que optarem por trabalhar ou estagiar em um turno; as opções de lazer e sociabilidade são exíguas; os equipamentos artístico-culturais são poucos e falta-lhes qualificação e profissionalismo; o afastamento geográfico pode ser até um fator de entrave à pesquisa e à formação de parcerias por parte dos docentes; paradoxalmente, os veículos oficiais da universidade não podem cruzar a fronteira, caso planejemos alguma atividade pedagógica ou intercultural com o país vizinho. Algumas pessoas veem este quadro como uma oportunidade para reinventar as relações internas do mundo acadêmico, através de uma esfera política mais endêmica que atua na criação de um discurso de "resistência da periferia"; outras o encaram idilicamente, às vezes até romanticamente, como um traço distintivo de uma universidade pública instalada no "interior profundo" do Brasil, este interior que precisa ser elevado a uma condição de 


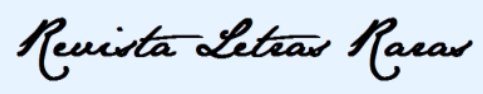

ISSN: $2317-2347$ - v. 7, n. 1 (2018)

progresso. Como não sou ufanista e não nutro utopias transformadoras, prefiro pensar nos impactos práticos e concretos que esta condição causa em minha atividade docente.

\section{Muitos escritores têm mantido atividade constante nas redes sociais, seja para promover a própria obra, seja para engajar-se politicamente. Você se mantém afastado das redes desde o princípio. Por quê? E como vê essa face do intelectual contemporâneo?}

Poucas coisas me interessam no mundo virtual, da tecnologia e da internet. Trata-se de um mundo paralelo, holográfico, meio fantasmagórico. Tenho um certo temor em relação ao futuro, quando teremos desmantelado por completo a noção de uma esfera privada em favor de uma vida despersonalizada, onde tudo terá se tornado público (no pior sentido deste termo), inclusive a intimidade de cada um. Muitas pessoas acreditam que as redes sociais as "individualizaram", deram-lhes uma "voz", uma plataforma de discurso e intensificação de identidades. É o contrário: o que as redes sociais fazem é gerar uma massa paranoica, desfigurada, hiperfriccionada e sempre prestes a se manifestar - ainda que, na maior parte das vezes, esta massa diga apenas frivolidades, já que a precipitação e a displicência estão em seu DNA. E a massa - não nos esqueçamos do alerta de Ortega y Gasset - é um monstrengo social. Não tenho interesse em participar das agruras, das disputas e do jogo de cena das redes sociais. Se engajar-se politicamente significa perder horas com postagens que expõem ameaças, estimulam a perseguição e disseminam o ódio, então, isso não me interessa. Não vejo engajamento político nisso: vejo histeria coletiva. Em certa medida, o intelectual público - aquela figura que líamos, que esperávamos ansiosamente ouvir numa entrevista ou numa palestra, aquela figura cujas ideias constituíam um horizonte definhou paralelamente à ascensão de uma massa opinativa parasitária que, sob o pretexto de defender a diversidade de ideias, vem instituindo formas autoritárias de representação da realidade e de construção de um debate público. Atualmente, como pode o intelectual público manter-se relevante? Como isso pode acontecer se, na esfera intelectual (hoje a esfera da mídia), ele tem que disputar espaço com celebridades, adolescentes descoladinhos que fazem macaquices diante de uma câmera (os chamados youtubers), influenciadores digitais com seu arsenal de receitas prontas para tudo, 


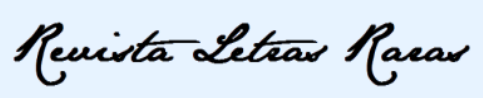

ISSN: 2317-2347 - v. 7, n. 1 (2018)

produtores de banalidades e líderes religiosos donos de redes de comunicação? Um fenômeno paradigmático deste mundo das redes sociais é o fato de que, hoje, mede-se a extensão, a abrangência, o impacto e a relevância das ideias e do pensamento pela quantidade de likes que eles podem gerar. Assombroso! O mundo das redes sociais é o mundo da superfície, da opinião, da autofagia. Enfim, eu detestaria ter "seguidores". Quem tem seguidores é o Dalai Lama, o Papa...

\section{Diante do panorama da literatura brasileira atual, o que você vê? Que autores você tem lido? Gostaríamos que você nos falasse um pouco sobre suas principais inquietações e estímulos em face da produção literária - sobretudo poética - brasileira contemporânea.}

Penso que há, de um lado, a literatura; e, de outro, o meio literário. São duas coisas distintas. O meio literário é corporativo, exclusivista, esotérico. Você nunca consegue saber o que seus integrantes estão arquitetando. Mas isso não me preocupa. $\mathrm{O}$ que me interessa é a literatura, a criação, o labor de pessoas que podem estar no mais completo anonimato e, ainda assim, produzindo trabalhos de qualidade. No momento atual, percebo a atuação de um dogma literário que vem sendo instituído nos últimos tempos, o qual direciona temas, abordagens e parâmetros para a efervescência do mercado (tanto financeiro quanto das ideias). Minha relação com a literatura não é técnica nem cerebral, é intuitiva e emocional. Meus filtros e detectores servem para a criação de um valor individual. Nunca indico livros e leituras a ninguém: cada um que descubra o que lhe apraz. Acho extremamente enfadonhos os círculos de debate literário. Não tenho conhecimento suficiente acerca de tudo que se produz no Brasil em termos poéticos. Há muita gente escrevendo e publicando, há várias editoras, patrocínios, canais de divulgação... É quase impossível acompanhar isso tudo, nem tenho a pretensão de fazê-lo. Penso que o principal desafio da literatura brasileira atual é manter um nível aceitável de leitura e de hermenêutica do texto literário diante de um país semiletrado, no qual, cada vez mais, cresce o analfabetismo funcional e despenca a qualidade da educação básica. No momento, no âmbito da poesia, estou lendo os Poemas Reunidos de Ivan Junqueira (Record, 1999) e o livro Ignorância do sempre de Juliano Garcia Pessanha (Ateliê Editorial, 2006). 


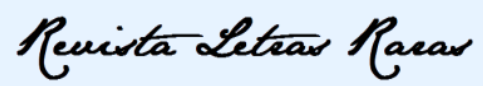

ISSN: $2317-2347$ - v. 7, n. 1 (2018)

Em 2014, você editou por conta própria Universo, um pequeno volume composto por um único poema que percorre todas as páginas, à maneira de um verso sem fim. Por outro lado, seu livro seguinte foi editado pela Modelo de Nuvem e foi finalista do mais importante prêmio literário do Rio Grande do Sul. Quais os principais desafios para a edição de novos escritores no Brasil de hoje?

O principal desafio é manter-se íntegro e honesto consigo mesmo diante das investidas de um mercado editorial para o qual a qualidade do texto literário deixou de ser um parâmetro. Evidentemente, não se pode generalizar, pois há boas editoras e bons profissionais (editores) que fazem um trabalho bastante sério. No mundo atual, é relativamente fácil publicar. Você pode editar por conta própria; há verbas disponíveis através de leis de incentivo à cultura ou patrocínio privado; há quem publique através de financiamento coletivo (crowdfunding). Já há produtores culturais e agentes literários especializados no suporte aos novos escritores. Os meios digitais - importantes neste caso - possibilitaram publicações mais baratas e de circulação mais abrangente. Outro desafio, além do exposto acima, consiste em destacar-se num cenário hipersaturado do ponto de vista da produção de ideias e de pensamento criativo. O mundo atual desvaloriza a experiência pregressa, o cultivo de uma trajetória e o amadurecimento que se associa ao estudo, ao aprimoramento e à autossuperação (aquilo que um dia definiuse como Bildung). Veja-se, por exemplo, o caso da dupla Neagle, que são dois primos que venderam milhares de exemplares na recente Bienal do Livro do Rio de Janeiro. Sua experiência, do alto de seus dezenove anos de idade, consiste na publicação de vídeos no Youtube em que passam o tempo fazendo malabarismo com garrafinhas de água...

Em outro poema de $A$ orientação das serpentes (2016), lemos os seguintes versos: "Este é um tempo em que abutres / pairam sobre o mundo, / escandalosamente desejosos / de nossa carne desumana." Como se não bastasse abutres pairarem sobre o mundo, a carne que eles almejam é desumana. Atualmente, no Brasil e no exterior, vivemos a ascensão de uma onda reacionária que traz em si matizes racistas, fascistas, misóginos e homofóbicos. Gostaríamos que você nos ajudasse a 


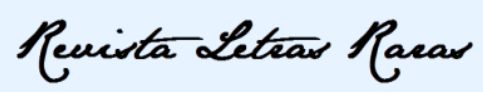

ISSN: 2317-2347 - v. 7, n. 1 (2018)

compreender: onde estava guardada tanta monstruosidade? Houve um ponto ou marco crucial para a detonação de uma circunstância como esta que vivemos hoje? O que você imagina ou espera como coda do atual estágio da humanidade?

A monstruosidade é constitutiva do mundo humano em todos os tempos e épocas. Não é prerrogativa do momento atual. Poderíamos escrever uma história da humanidade pelo viés da violência, da morte e do mal. Tal história demandaria muitos volumes impressos. O século XX (para ficar em apenas um século!) presenciou guerras mundiais, genocídios (judeus, armênios, tutsis...), perseguições, sistemas políticos totalitários. O ser humano não tolera a paz. O amor é pesado demais para a nossa espécie. O diálogo, para nós, tem a forma de uma bola de demolição. É sempre mais simples, portanto, resolver os dilemas humanos com uma ogiva nuclear. Assim, não sei se entendi bem a pergunta, pois ela fala de uma circunstância que "vivemos hoje" e, no meu entendimento, o que vivemos hoje é uma extensão ou um desdobramento do que temos plantado por séculos de soberba e vaidade. Diante deste quadro, não ouso propor qualquer caminho ou conduta que possam nos livrar de tanta desolação. Mas penso, todavia, que se faz urgente resgatar um sentido de espiritualidade diante do mundo, uma espiritualidade que possa nos confrontar com nossa impotência, que nos reconecte à natureza e à ecologia, que nos fale do profundo da vida, enfim, uma espiritualidade que seja capaz de nos despertar e iluminar diante da casuística materialista do mundo contemporâneo.

Você está escrevendo algum livro no momento? Possui projetos que envolvam outros gêneros literários?

No momento, trabalho em um livro de poemas que pretendo publicar em 2019. Por meio destes poemas, pus-me a refletir sobre a comunicação humana, o diálogo, o discurso, o argumento, e sobre aquilo que torna esses elementos tão contraditórios e explosivos. Também estou trabalhando em um livro que resulta de um projeto de pesquisa cadastrado junto à Unipampa, no qual estou analisando o processo de rejeição ao monumento a Nossa Senhora de Caravaggio ocorrido na cidade de Farroupilha-RS. 


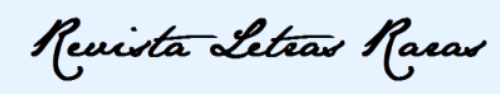

ISSN: 2317-2347 - v. 7, n. 1 (2018)

Este projeto tem previsão de encerrar-se em 2018 e, portanto, poderá ser publicado também em 2019. No âmbito literário, exercito-me exclusivamente na poesia.

\section{REFERENCIAS}

AGAMBEN, G. O que é o contemporâneo? e outros ensaios. Trad. Vinícius Nicastro Honesko. Chapecó, SC: Argos, 2009.

DA ROLT, C. Canção de vidro. Porto Alegre: WS Editor, 2004. Universo. Jaguarão: Edição do autor, 2014. . A orientação das serpentes. Porto Alegre: Editora Modelo de Nuvem, 2016.

DA ROLT, C.; CECCAGNO, D.; ARENDT, J. C.; TASCA, M. Calendário - Antologia Poética do Grupo Neblina. Bento Gonçalves: Edição dos autores, 2006.

Data de recebimento: $18 / 03 / 2018$

Data de aceite: $27 / 04 / 2018$ 